\title{
Falsification by Modelling and Simulation for Investigations in Hallstatt Archaeology
}

\author{
Johannes Tanzler ${ }^{1 *}$, Niki Popper ${ }^{1}$, Gabriel Wurzer ${ }^{2}$, Anke Bacher ${ }^{2}$, Kerstin Kowarik ${ }^{3}$, \\ Hans Reschreiter ${ }^{3}$, Felix Breitenecker ${ }^{1}$
}

${ }^{1}$ Institute of Analysis and Scientific Computing, TU Wien, Wiedner Hauptstraße 8-10, 1040 Vienna, Austria; *johannes.tanzler@tuwien.ac.at ${ }^{2}$ Institute of Architectural Sciences, TU Wien, Treitlstraße 3, 1040 Vienna, Austria

${ }^{3}$ Natural History Museum Vienna, Burgring 7, 1010 Vienna, Austria

SNE 28(3), 2018, 129 - 132, DOI: 10.11128/sne.28.sn.10436 Received: Sept. 15, 2016 (Selected EUROSIM Congress 2016 Postconf. Publ.), Revised Aug. 25, 2018, Accepted: Sept. 5, 2018 SNE - Simulation Notes Europe, ARGESIM Publisher Vienna, ISSN Print 2305-9974, Online 2306-0271, www.sne-journal.org

Abstract. The prehistoric salt mines of Hallstatt in Austria are subject of great interest for archaeologists. Salt mining activities are dated to $1458-1245$ B.C. in the Bronze Age. Modelling and simulation as virtual computational experimental archaeology' can contribute important insights into different areas of archaeology as an addition to traditional experimental methods. In a cooperative project between the Natural History Museum Vienna and the TU Wien, questions regarding prehistoric mining processes, logistic processes, and population growth in the agricultural environment are analysed by modelling and simulation. This contribution presents simulation studies, which allow to study short-term mining processes and long-term population dynamics and agricultural working processes. Moreover, essentially, the simulation studies allow also excluding cases for these working processes. This fact underlines a special property of simulation in the area of archaeology: while classical modelling and simulation aims for verification of a certain assumptions, modelling and simulation in archaeology partly aims for falsification of assumptions of working processes or other historic events.

\section{Introduction}

The prehistoric salt mines of Hallstatt in Austria are subject of great interest for archaeologists, not only for their technological aspects, but also for their complex economic structure. Salt mining activities are dated to 1458-1245 B.C. in the Bronze Age $[1,2]$.

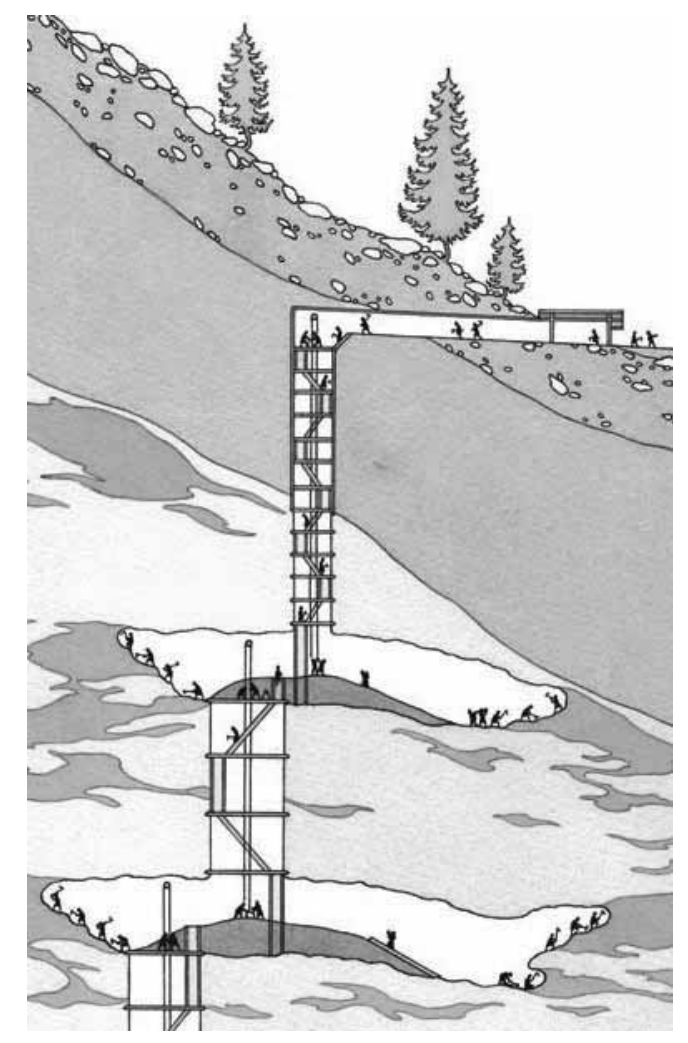

Figure 1: Schematic reconstruction of the mining halls and shaft structure with rope pull systems (๔ D. Gröbner, H. Reschreiter, NHM Vienna).

A large amount of archaeological findings of technical equipment and organic materials (timber, wooden tools, strings of bast, fur, etc.) and the perfect conditions of preservation in the mines due to the conserving properties of salt allow for a reconstruction of the working process in the mines and in the environment of the mines. Archaeologists develop a technological reconstruction in form of a mental model which suggests that mining was organized in an efficient, nearly industrial manner with highly specialized tools. 
Salt was mined in underground mining chambers (Figure 1) using special bronze picks. The broken salt was collected in buckets and carried to the vertical shaft where it was hoisted to the surface using a woolsack or cloth attached to a linden bast rope.

The high degree of specialization and functionality observable on certain tools and the design for high efficiency suggest that the workforce had highly specialized knowledge in mining technology and infrastructure [2]. Furthermore, the mineworkers were dependent on the population environment, including cultivating and harvesting the surrounding land, and on proper logistic transport processes for salt (outbound), necessary goods, which could not be, produced onsite (outbound), and partly on food delivery (in-bound).

The mental models - for the short-term mining process and for the long-term cultivation and harvesting processes and for the population dynamics raise further questions, which need to be formalized and - in case of the short-time processes - are typically investigated in experiments using re-constructions of prehistoric tools and utilities (experimental archaeology). Modelling and simulation as virtual computational experimental archaeology can also help to gain knowledge about technological issues and allow comparing different scenarios. Results of this work (experiments and simulation) and their interpretation then allow archaeologists to make conclusions about the technological concept and together with new excavation findings update their mental model leading to an iterative process.

Simulationists are faced with an interesting change of the aims of a simulation study. Because of only little evidence and only few findings, assumptions on the processes to be analysed by modelling and simulation cannot be really validated and verified - so an opposed strategy is often the better one: assumptions are falsified by modelling and simulation [3], so that after some 'falsifications' the nature of the processes comes up.

\section{Short-time Mining Processes}

Already in bronze age mining was a complex working task, with need for tools, and need for supply. Most important were tools for direct mining - bronze picks, tools for transport - buckets and rope systems, and tools for lightning.

Use of Bronze Picks. Archaeologists know from excavation findings that the salt was mined using bronze picks with wooden handle ([2], Figure 2).

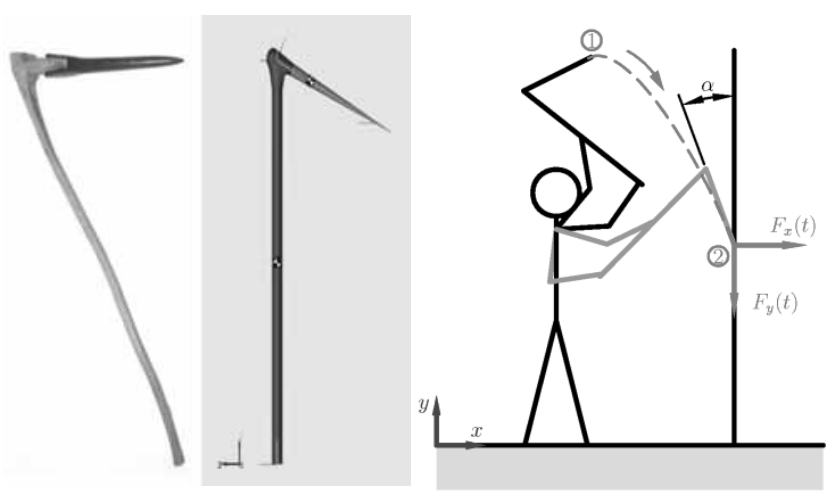

Figure 2. Bronze pick for salt mining: archaeological reconstruction (left; @ A. Rausch, NHM Vienna), pick rigid body model (midst), and supposed trajectories for use of the pick (right).

Highly interesting is the unusual shape of these picks with a typical angle between the shaft and tip of about 55 to 75 degrees. It is believed that this particular shape was adapted to the specific working conditions in the Hallstatt mines. The small angle does not allow typical circular hacking motion - it is not yet completely clear how such a pick was used.

Modelling the pick as a rigid body system (Figure 2, midst and right) allows dynamic simulation and evaluating possible movement scenarios. Two phases are considered in the model setup by mechanical component modelling ([4]): free motion - pick accelerates along a fixed trajectory, and when collision with the wall is detected - the body decelerates until it comes to a stop.

Different usage of the pick can be considered, e.g. breaking the salt on the wall or on the floor, different grip points, using one or two hands, etc. (detailed results in [4]). Other scenarios like mining the salt on horizontal or inclined surfaces are also currently investigated. However, simulation shows that mining on the floor seems more exhausting, requires more energy and is therefore less efficient than mining on the wall - an example for falsification by modelling and simulation.

Use of Rope Pull Systems. Rope pull systems were used to hoist the broken salt from the mining halls through shafts to the surface $([3,4]$, Figure 1 and Figure 3).

While there are archaeological findings of bast ropes and other appliances, there are still some matters regarding the construction, length and arrangement of the rope pull systems at issue. 

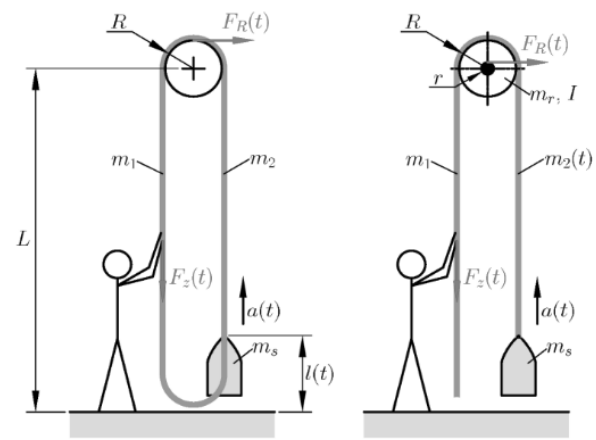

Figure 3. Different design options for the rope pull system with closed rope (left) or open rope (right).

To estimate and compare the time and strength requirements for transporting the salt, various options are analysed using simulation models. For example, two variants of the rope design, an open and a closed version, is analysed (Figure 3). An important issue also concerns modelling of the rope guide, for which two possibilities, one with sliding friction on a $\log$ and one with return pulley are considered.

Balance of forces, mass of the rope, forces of inertia, coulomb friction force lead to a partly nonlinear model for the rope dynamics [4]. The model was implemented in MATLAB. In summary, the simulation results show significant force requirement for the model with sliding friction, especially because of the high mass of the rope. This is also the reason for limitations regarding the maximum allowed shaft height (detailed results in [4]).

\section{Woodchip, Lighting and Air Consumption.}

During mining, burning sticks of wood served as the only illumination in the mining halls (Figure 1). Burnt down woodchips were found during excavation in large quantities. The resulting light intensity depending on the number of burning woodchips can be estimated using a uniform arrangement in a mining hall.

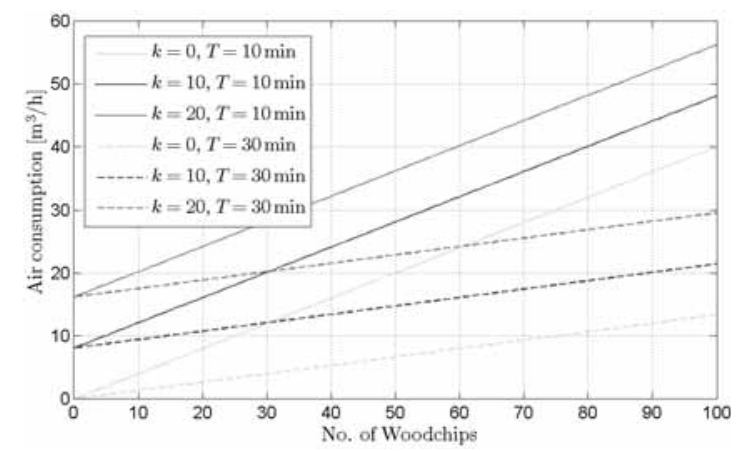

Figure 5. Simulation results for air consumption depending on number of woodchips, burning time $T$ and workers $k$.
Furthermore, some static calculations help estimating the oxygen consumption of the flames, which, in addition to the oxygen demand of the workers, give information about the necessary air ventilation. Figure 5 shows interesting simulation results with respect to air consumption - giving hints for possible numbers of miners and length of mining shifts.

\section{Long-time Working Processes and Supply of Population}

Long-time case studies give a clue how many people, including the mine workers, could have been fed by harvesting the surrounding land. It seems likely that some of the gathered salt was used to be exchanged for food, but the question is how much additional food was needed. Basis for these case studies is agent-based modelling and simulation of the population dynamics and working dynamics, from mining to harvesting.

Generally, the village is assumed to be located close to the mine and almost all fields beside the grass fields are located in the valley (Figure 5).

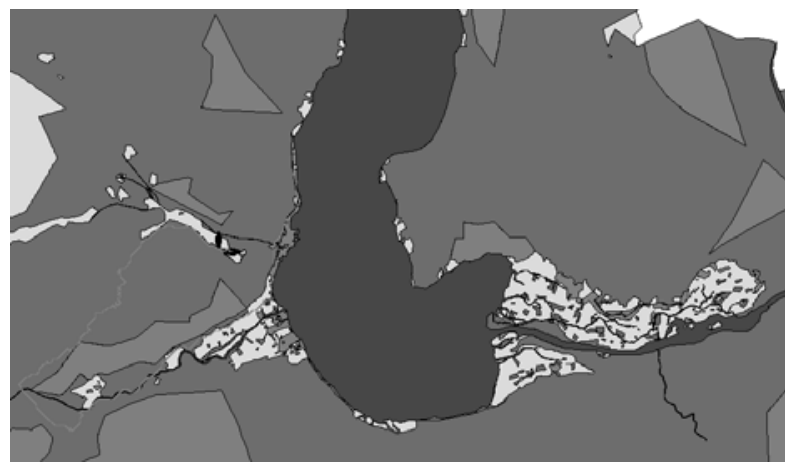

Figure 5: Map of Hallstatt area: at left hill with mining area and mining village, at right valley with agricultural area (lake - blue, garden -red, field - brown, grass - light green, wood - dark green, rock -grey).

Possible Stable Population. A basic question is, how many people lived in the Hallstatt prehistoric village. Based on the nutrition facts and the average energy consumption of a person, an agent-based model for the population can be derived ([5]). Simulations over 300 years result in a partly stable population for survival.

Various scenarios are simulated and allow falsification of unrealistic assumptions. For instance, depending on weather influences simulation is used to show the amount of each type of nutrition that has to be bought or that is over produced (Figure 6). 


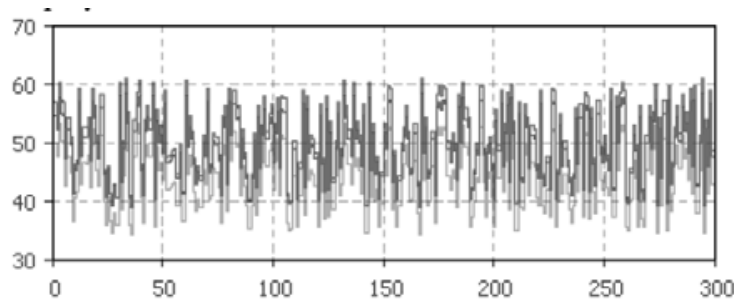

Figure 6. Simulation results with variation of food composition (green: available/used meat, red: available/used beans, blue: available/used grain)

Overall Working Processes. In bronze age, in Hallstatt complex working processes have been set up. Agent-based modelling and simulation allows to study the co-operation of these processes, from mining via food supply to harvesting and socialising.

Basis is a population dynamic with estimated birth and death gathered from another project. The relevant working procedures are:

- seeding and mowing

- harvesting

- wood production

- wood chip production

- salt mining

The scheduling of the workload is highly dependent on the date especially concerning the agricultural tasks. When the optimal day for a specific task has come, an agent gets a task assigned in the morning, then goes to the location and performs it. Afterwards the agent gets the next task and directly heads to the next area which has not been processed yet. To minimize the walking time, it is estimated how many people have to work on the specific area.

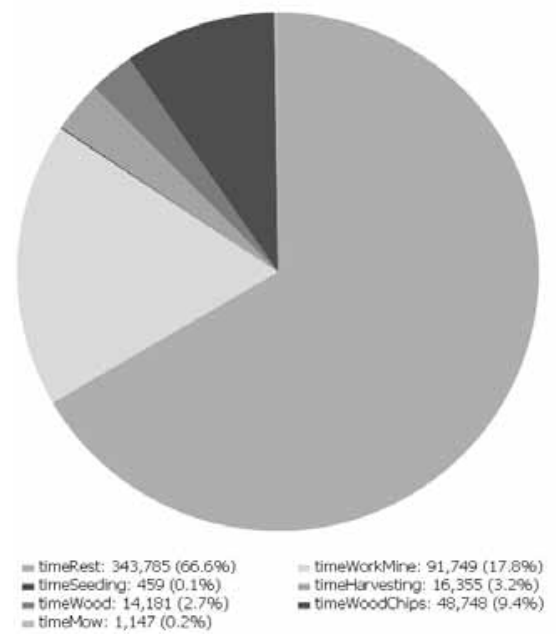

Figure 7: Overall distribution for working processes.
On days without agricultural work, the agents are assigned to work in the mine if there are enough woodchips in the stock to light the mine. Otherwise the task is to make wood chips, or if there is not enough wood, to manage to get some.

The results of these simulations studies are mainly individual and overall time distributions for the working processes. Emphasis is put on working time in the mine, which allows to estimate the salt production. Figure 7 shows an overall distribution for the working processes

Second Settlement. The miners' village is assumed to be located close to the mine, and almost all fields are located in the valley. This raises the guess for a second settlement in the valley (on place of nowadays Hallstatt) with advantages of shorter distances for harvesting.

The model allows such a case study, and indeed the simulation results show that the assumption of a second village in the valley is a promising alternative, with a better efficiency of workload scheduling.

\section{Conclusion}

The simulation case studies presented indeed allowed to exclude some assumptions on working processes in the salt mine and in the agricultural environment - underlining the importance of modelling and simulation for 'falsification' in archaeological research.

\section{References}

[1] Grabner M, Reschreiter H, Barth F E, Klein A, Geihofer D, Wimmer R. Die Dendrochronologie in Hallstatt. Archäologie Österreichs, 17(1), pp. 49-58.

[2] Reschreiter H, Kowarik K. The Bronze Age. In: Kern et al. Kingdom of Salt: 7000 Years of Hallstatt. Vienna: VPA3, Natural History Museum Vienna, 2009, pp. 48-64

[3] Popper N. Comparative Modelling and Simulation: A Concept for Modular Modelling and Hybrid Simulation of Complex Systems. PhD Thesis, TU Vienna, 2015.

[4] Heinzl B, Auer E, Slowacki B, Kowarik K, Reschreiter H, Popper N, Breitenecker F. Physical Modelling for Hallstatt Archaeology. Simulation Notes Europe SNE 22(1), 2015, pp 25-32, doi: 10.11128/sne.22.tn.10109

[5] Tanzler J, Pichler P, Kowarik K, Reschreiter H, Wurzer $\mathrm{G}$, Bacher A, Breitenecker F. Modelling agricultural constraints for population size in prehistoric Hallstatt. Proc. ERK Conference Portoroz Sept. 2013, IEEE Slovenia Publ., 2013, pp 157-160

[6] Breitenecker F, Bicher M, Wurzer G. Agent-based modeling and simulation in archaeology, chapter: AgentBased Simulation in Archaeology: A Characterization. [S.1.]: Springer, 2013. 